\title{
Developmental expression of $C O E$ across the Metazoa supports a conserved role in neuronal cell-type specification and mesodermal development
}

\author{
Daniel J. Jackson • Néva P. Meyer • Elaine Seaver • Kevin Pang • Carmel McDougall • \\ Vanessa N. Moy • Kacy Gordon • Bernard M. Degnan • Mark Q. Martindale • \\ Robert D. Burke $\cdot$ Kevin J. Peterson
}

Received: 24 September 2010 / Accepted: 19 October 2010/Published online: 11 November 2010

(C) The Author(s) 2010. This article is published with open access at Springerlink.com

\begin{abstract}
The transcription factor $C O E$ (collier/olfactory-1/ early B cell factor) is an unusual basic helix-loop-helix transcription factor as it lacks a basic domain and is maintained as a single copy gene in the genomes of all currently analysed non-vertebrate Metazoan genomes. Given the unique features of the $C O E$ gene, its proposed ancestral role in the specification of chemosensory neurons and the wealth of functional data from vertebrates and Drosophila, the evolutionary history of the $C O E$ gene can be readily investigated. We have examined the ways in which $C O E$ expression has diversified among the Metazoa by analysing its expression from representatives of four disparate invertebrate phyla: Ctenophora (Mnemiopsis leidyi); Mollusca (Haliotis asinina); Annelida (Capitella teleta and Chaetopterus) and
\end{abstract}

Communicated by D.A. Weisblat

Electronic supplementary material The online version of this article (doi:10.1007/s00427-010-0343-3) contains supplementary material, which is available to authorized users.

D. J. Jackson • C. McDougall • B. M. Degnan

School of Biological Sciences,

University of Queensland,

Brisbane 4072, Australia

D. J. Jackson $(\square)$

Courant Research Centre Geobiology,

Georg-August University of Göttingen,

Goldschmidtstr. 3, 37077,

Göttingen, Germany

e-mail: djackso@uni-goettingen.de

N. P. Meyer $\cdot$ E. Seaver $\cdot$ K. Pang $\cdot$ M. Q. Martindale University of Hawaii, Kewalo Marine Laboratory,

41 Ahui Street,

Honolulu, HI, USA 96813
Echinodermata (Strongylocentrotus purpuratus). In addition, we have studied COE function with knockdown experiments in S. purpuratus, which indicate that COE is likely to be involved in repressing serotonergic cell fate in the apical ganglion of dipleurula larvae. These analyses suggest that $C O E$ has played an important role in the evolution of ectodermally derived tissues (likely primarily nervous tissues) and mesodermally derived tissues. Our results provide a broad evolutionary foundation from which further studies aimed at the functional characterisation and evolution of $C O E$ can be investigated.

Keywords COE $\cdot$ Ectoderm $\cdot$ Mesoderm $\cdot$ Neurogenesis $\cdot$ Metazoa

V. N. Moy $\cdot$ K. Gordon $\cdot$ K. J. Peterson Department of Biological Sciences, Dartmouth College, Hanover, NH, USA 03755

\section{R. D. Burke}

Department of Biology, Department of Biochemistry/

Microbiology, University of Victoria,

Victoria, POB 3020, STN CSC,

Victoria, BC, Canada V8W 3N5

Present Address:

K. Gordon

Department of Organismal Biology and Anatomy,

The University of Chicago,

1027 East 57th Street,

Chicago, IL 60615, USA 


\section{Introduction}

Understanding the molecular events that supported the morphological expansion of metazoan body plans is a fundamental aim of evo-devo studies. With the increasing availability of whole genome datasets from a variety of metazoan taxa (Sea Urchin Genome Sequencing Consortium, 2006; Putnam et al. 2007, 2008; Chapman et al. 2010; Srivastava et al. 2010), a growing challenge is to identify common (and truly homologous) genomic outputs and to assess the similarities and differences in their functions across a phylogenetically informative spread of representatives. Such studies hold the potential to provide deep insight into the features that common ancestors were likely to have possessed, and the events that accompanied the genesis and expansion of new clades of animals in the pre- and early Cambrian (Martindale 2005; Wheeler et al. 2009). The identification of deeply conserved developmental patterning mechanisms, such as the Hox code (or at least the precursors to such genes), support the notion that the metazoan ancestor possessed a developmental toolkit of genes that has been modified in lineage-specific ways to generate disparate body plans (Carroll et al. 2001; Larroux et al. 2006; Adamska et al. 2007). Related to the notion of a conserved developmental toolkit is the suggestion that cell types have specific 'molecular fingerprints' that can be used to identify cellular homologies across taxa (Arendt 2008). Explicitly, this concept interprets the expression of orthologous genes in similar tissues at similar times as an indication of cellular homology (Arendt 2005); however, it must be pointed out that when comparing the expression of homologous genes between cells, tissues or organs, structures that share homologous gene expression are not necessarily homologous in themselves; for example, orthologs of the gene Distal-less pattern many non-homologous structures across the Metazoa. This important point led Claus Nielsen to coin the term 'homocracy' in order to distinguish between nonhomologous structures patterned by homologous genes (Nielsen and Martinez 2003). True homology of cells, tissues or organs is more convincingly demonstrated on the molecular level by the synexpression of a demonstrable gene regulatory network (GRN), as such a network is presumably less likely to be co-opted to a non-homologous structure than an individual gene (Davidson 2006). A clear example of this was provided by Dunn et al. (2007) to demonstrate that apical sensory structures of larval urchins and gastropods are unlikely to share homology. They conducted a GRN analysis to test the hypothesis that the apical tufts of larval urchins and gastropods were homologous. In many marine invertebrates, the apical end of the larval body plan consists of what is termed the apical organ, which generally consists of two components: the ciliated apical tuft and the apical ganglion. Because the apical tufts of urchins and gastropods use different GRNs for their specification, Dunn et al. (2007) argued that they were the result of convergent evolution, at least in these two taxa, sometime in the late Precambrian (Peterson 2005).

The transcription factor COE was first isolated from vertebrate models and ascribed a role in regulating the expression of olfactory (Wang and Reed 1993) and immune cell fates (Hagman et al. 1993; Travis et al. 1993). A Drosophila homolog of COE was isolated shortly after the vertebrate gene (Crozatier et al. 1996) and has been found to play a variety of roles, including head segmentation (Crozatier et al. 1999), wing patterning (Crozatier et al. 2002), muscle specification (Crozatier and Vincent 1999) and immune cell specification (Crozatier et al. 2004). Vertebrate paralogs of COE have also been reported to play roles in limb development (Mella et al. 2004), and a recent analysis of ascidian development suggests that the last common ancestor of the Chordata may have used COE to specify pharyngeal mesoderm development (Stolfi et al. 2010). Pang et al. (2004) reported that $C O E$ expression is restricted to the apical organ (the ciliated and innervated structure at the aboral end of the developing planula larva) of the cnidarian Nematostella vectensis, suggesting that the ancestral eumetazoan function of COE was to specify chemosensory neurons. This last study provides an evo-devo foundation from which the interpretation of various studies demonstrating a role for COE in vertebrate (Wang and Reed 1993; Garel et al. 1997; Dubois et al. 1998; Pozzoli et al. 2001; Corradi et al. 2003; Garcia-Dominguez et al. 2003) and invertebrate (Prasad et al. 1998; Baumgardt et al. 2007) neurogenesis can be placed.

These previous studies, primarily focused on vertebrate models, Drosophila and C. elegans, indicate that COE is highly pleiotropic and plays important roles in the specification of cell types originating from all three embryonic germ layers (Liberg et al. 2002). Here, we have isolated the $C O E$ homologues from a variety of invertebrate metazoans and investigated their expression patterns with the goal of uncovering conserved and divergent features of COE expression. COE displays complex expression patterns in all taxa investigated; however, broad commonalities and differences can be identified. Our results suggest that COE may be part of a molecular fingerprint specific to a subset of ectodermally derived cell types, possibly chemosensory, non-serotonergic and located in the anterior ciliated structures. We stress that this proposed cell type homology neither requires nor implies homology of apical organs; apical ganglia may consist of homologous cell types, but apical tufts could be the products of convergent evolution (see "Results and discussion"). Early mesodermal expression of COE in ctenophores, protostomes and vertebrates suggests another shared function may relate to 
the development of the haematopoietic system and/or connective tissue differentiation (Hagman et al. 1993; Akerblad et al. 2002).

\section{Materials and methods}

Gene isolation, whole mount in situ hybridization and MASO injections

For all organisms, previously published protocols for RNA extraction, gene isolation and RACE PCR were employed (for example see Jackson et al. 2005; Matus et al. 2006; Dunn et al. 2007; Thamm and Seaver 2008). Where genomic or EST sequences were available, these were first searched and used to design gene-specific primers for RACE PCR. Organism-specific methods for whole mount in situ hybridizations (WMISH) were employed for the ctenophore Mnemiopsis leidyi (Pang and Martindale 2008), the tropical abalone Haliotis asinina (Jackson et al. 2007), the annelids Capitella teleta (Thamm and Seaver 2008; Blake et al. 2009), previously Capitella sp. I (Blake et al. 2009) and Chaetopterus (Boyle and Seaver 2010), and the sea urchin Strongylocentrotus purpuratus (Dunn et al. 2007). Newly obtained $C O E$ sequences have been deposited in GenBank
HQ529594 - HQ529597. SpNK2.1 morpholino anti-sense oligonucleotide (MASO) and SpCOE-MASO injections were performed as described in Takacs et al. (2004). The sequences of the $S p C O E$-MASO and the standard control MASO are, respectively 5'-GATATGACGGTCTCCATCT TACTCC-3' and 5'-CCTCTTACCTCAGTTACAATT TATA-3'. All primer sequences are available from the authors upon request.

Immunofluorescence and imaging

S. purpuratus embryos were fixed in 4\% paraformaldehyde in filtered sea water for $15 \mathrm{~min}$ at room temperature and then post-fixed for $1 \mathrm{~min}$ in $-20^{\circ} \mathrm{C}$ methanol. Fixed embryos were rinsed in phosphate-buffered saline (PBS) then incubated in PBS containing 5\% normal lamb serum and $0.01 \%$ Tween 20 for $30 \mathrm{~min}$ at room temperature to reduce non-specific binding. Specimens were incubated in primary antibody for $16 \mathrm{~h}$ at $4^{\circ} \mathrm{C}$ with rabbit anti-serotonin (Chemicon, CA) (1:500) and mouse or rat antisynaptogamin B (1:800) according to Nakajima et al. (2004). Embryos were rinsed in PBS and incubated in goat anti-rabbit Alexa 488 (1:800) and goat anti-rat Alexa 568 (1:1500) (Molecular Probes). Preparations were examined and photographed with a Leica DM 6000 B epifluorescence microscope (Leica Microsystems) and Hamamatsu Orca-

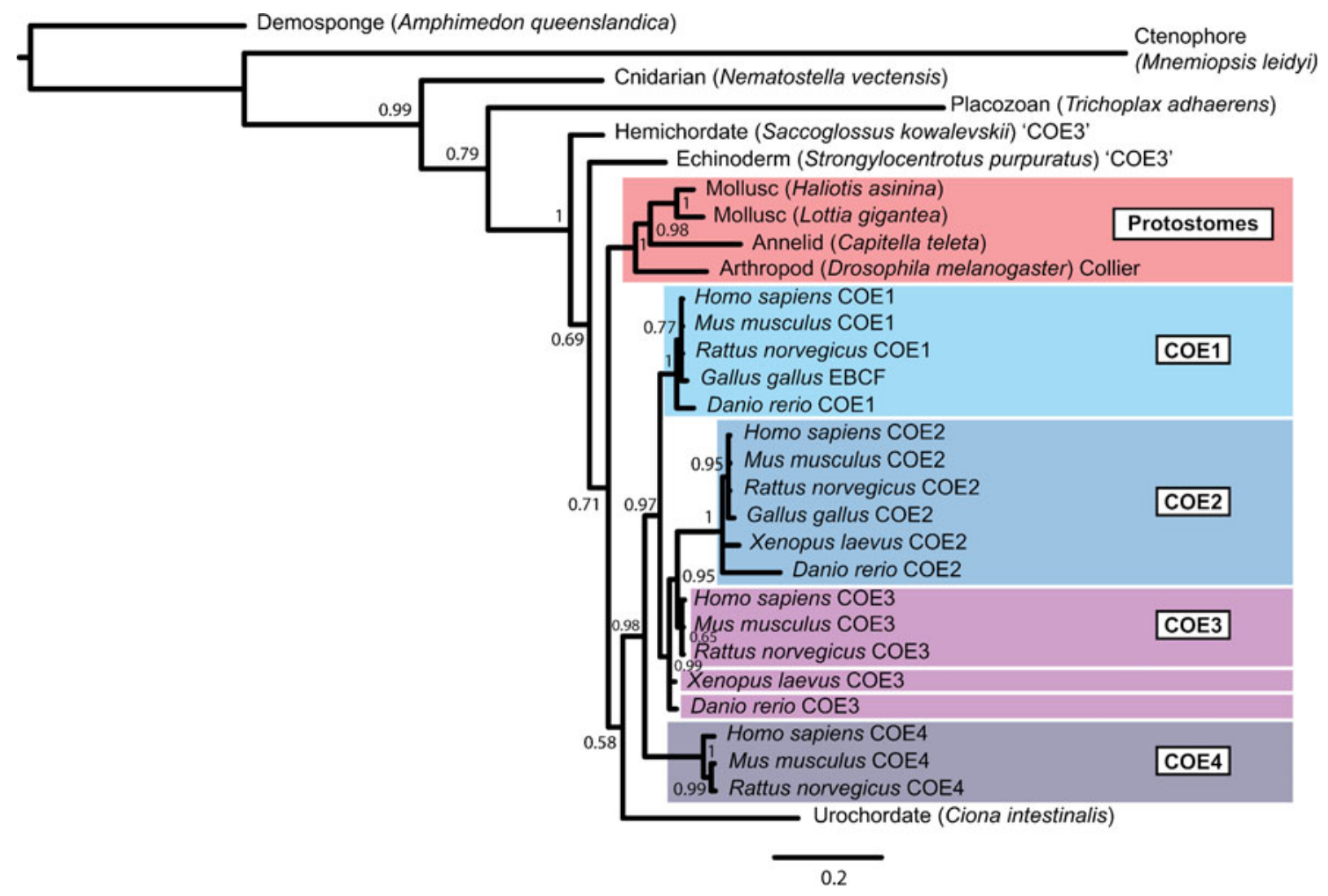

Fig. 1 Phylogenetic reconstruction of COE evolutionary history. The topology shown is a $50 \%$ majority rule tree derived from a Bayesian analysis of unambiguously aligned positions (see supplementary material for alignment). Posterior probabilities following 1.8 million generations are indicated 
ER camera (Hamamatsu Photonics) using Openlab 4.0.4. To determine the number of immunoreactive cells present, a double-blinded procedure was utilised such that näive observers examined specimens on a monitor focusing through the specimen to identify all immunoreactive cells. Statistical analyses were conducted using GraphPad Prism (4.03).

Phylogenetic analyses

COE homologues from a variety of metazoan taxa were retrieved from public databases following BLAST searches against GenBank and from whole genome draft assemblies of the placozoan Trichoplax adhaerens (see Supplementary Online Material for all accession numbers and genomic locations). These sequences were combined with full-length fragments isolated by RACE PCR and aligned using MUSCLE (Edgar 2004). Following manual adjustment (especially of the HLH region), the alignment was used to schematically represent conserved $\mathrm{COE}$ domains and was then processed by GBlocks (Talavera and Castresana 2007) to retrieve highly conserved positions for phylogenetic analysis. A Bayesian analysis of the resulting dataset was carried out with the parallel version of MrBayes (MrBayes v. 3.1.2p) on a Linux cluster at the Gesellschaft für wissenschaftliche Datenverarbeitung, Göttingen. The following settings were used: prset aamodelpr $=$ mixed nchains $=4$ nruns $=4$ temp $=0.2$ printfreq $=1000$ samplefreq $=1000$ ngen $=1800000$. A burnin value of $25 \%$ was set to exclude non-convergent tree topologies.

\section{Results and discussion}

Phylogenetic analyses

We isolated COE orthologs from the ctenophore M. leidyi, the polychaete annelid $C$. teleta the gastropod mollusc $H$. asinina, and the polychaete annelid Chaetopterus (HQ529594 - HQ529597). Our bayesian analysis recovered previously recognised vertebrate $\mathrm{COE}$ subfamilies (COE1, COE2 and COE4), although the COE3 subfamily was not recovered as a monophyletic group (Fig. 1). The branching order of these vertebrate subfamilies is concordant with a recent phylogenetic analysis of COE (Daburon et al. 2008), with COE4 apparently representing the most ancestral-like paralog of the vertebrate $C O E$ genes. All non-deuterostome bilaterian invertebrates (traditionally referred to as protostomes, however, see Martindale and Hejnol 2009 for an alternative view) form a monophyletic group, with spiralian taxa forming a well-supported subgroup. Early branching taxa (notably ctenophore and placozoan representatives)

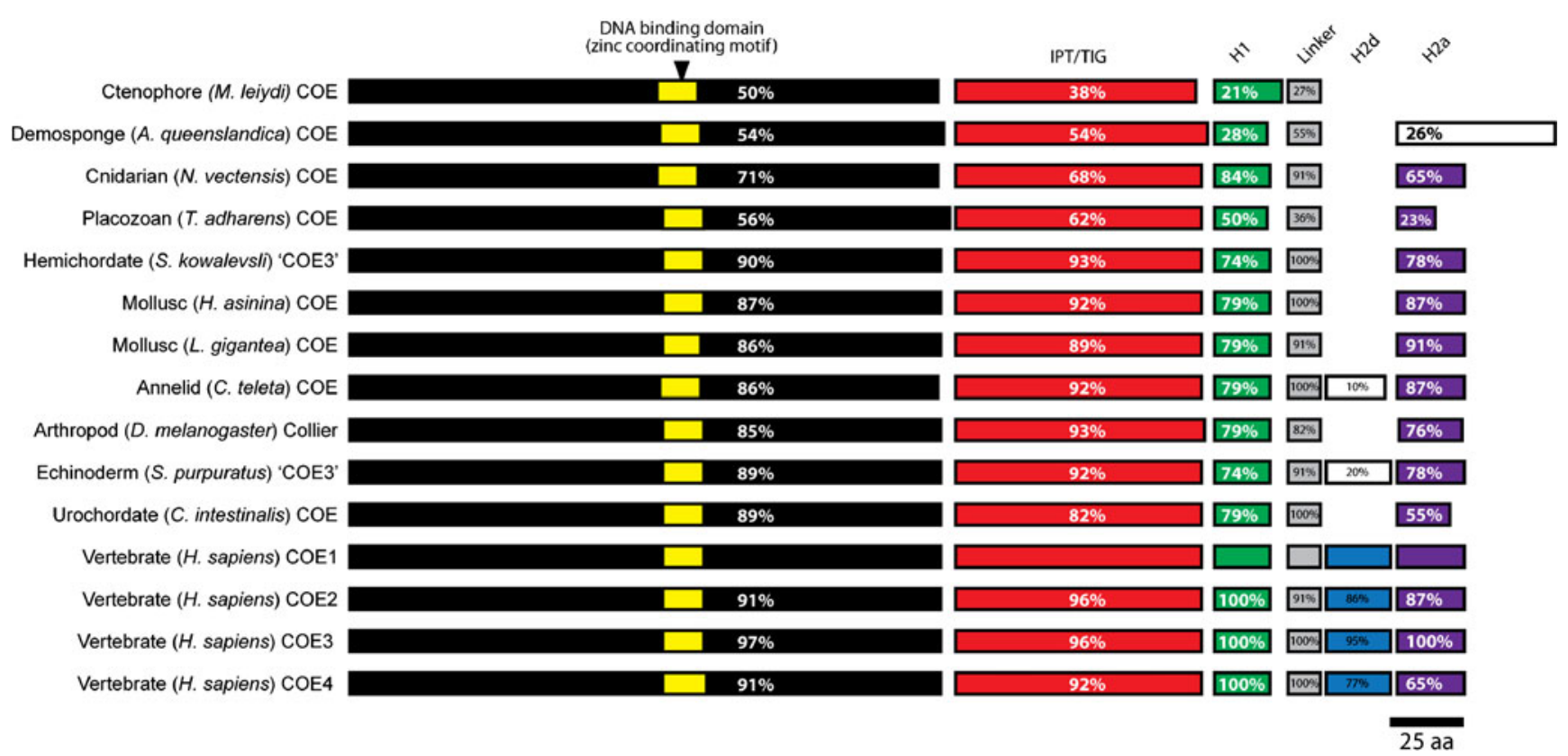

Fig. 2 Schematic representation of metazoan COE sequence architectures. The highly conserved nature of the DNA-binding domain (with the embedded zinc coordination motif), the IPT/TIG (immunoglobulin-like, plexins, transcription factors/transcription factor immunoglobulin) domain and the helix-loop-helix domains are indicated. Daburon et al. (2008) proposed that the second helix domain (H2d) is derived from the carboxyl-most helix domain (H2a), and we have followed this terminology here. Pairwise distances are indicated and were calculated using PAUP with human COE1 protein as the reference sequence. Only highly conserved alignable regions are shown, amino and carboxy regions are not included. All domain lengths are represented to scale 
display conspicuously long branches. This trend was also revealed by calculating pairwise distances for each conserved domain using the human COE1 protein as a reference (Fig. 2). In agreement with Daburon et al. (2008), our alignments, which include a wider representation of early branching taxa, also support the hypothesis that in the vertebrate lineage one of the alpha helices, $\mathrm{H} 2 \mathrm{~d}$, was derived from the carboxyl-most helix H2a (Fig. 2 and sequence alignment in Supplementary Online Material).

\section{COE spatial expression}

Ctenophore expression MlCOE expression begins at gastrulation; it is transiently expressed in the endomesodermal macromeres and in ectodermal micromeres associated with the blastopore (Fig. 3a, b). MlCOE expression persists in the macromeres and their daughters, the oral micromeres, which enter the blastocoel and give rise to future mesoderm (Fig. 3c, d). At later stages of gastrulation, MlCOE expression is maintained in these mesodermal cells as they migrate to a position underlying the apical ectoderm within the forming tentacle bulbs (Fig. 3e, g). At these stages, $M I C O E$ transcripts are also transiently detected in invaginating pharyngeal cells at the oral pole (Fig. 3e-h). MlCOE was not detected in the apical organ at any stage of development, including the free-swimming (cydippid) stages.

Lophotrochozoan expression COE expression in lophotrochozoan larvae is more complex, although there are several shared expression domains in H. asinina, Chaetopterus and
C. teleta (compare Figs. 4, 5, 6, 7, see detailed descriptions below). In contrast to Nematostella vectensis (Pang et al. 2004) and M. leidyi, all three lophotrochozoans express $C O E$ across a broad developmental time window. The three main domains of $C O E$ expression are in (1) subsets of mesoderm, (2) the developing nervous system and (3) small patches of ectoderm, including cells associated with the stomodeum and apical ectodermal cells. In all three lophotrochozoans, $C O E$ is expressed in a subpopulation of mesodermal cells (labelled as me in Figs. 4, 5, 6, 7). In $C$. teleta, COE is initially expressed in the mesodermal stem cells and their progeny (Fig. 4a, b), and soon becomes largely restricted to the mesodermal stem cells (Fig. 4e, f). In addition, there is a transient anterior-posterior wave of $C O E$ expression through the segmental trunk in the lateral mesodermal cell clusters (arrowheads, Fig. 5a-c). At any time point, there are one to two $C O E+$ cell clusters visible on each side of the animal and one cluster/segment. In the other two lophotrochozoans (H. asinina and Chaetopterus), development of the mesoderm is less well characterised, and at this time, we do not know to what differentiated structures the $C O E+$ populations of mesodermal cells contribute. In $H$. asinina, mesodermal expression of $C O E$ is evident in what are likely to be descendents of $4 \mathrm{~d}$ (Hejnol et al. 2007), the mesodermal bands (Fig. 6a, b, i, j). In Chaetopterus, COE also is expressed in distinct subsets of trunk mesoderm (Fig. 7a, b, e, f, i, j). Shared mesodermal expression in the three lophotrochozoans examined is intriguing considering the mesodermal expression of MICOE in the ctenophore M. leidyi (Fig. 3e) and the
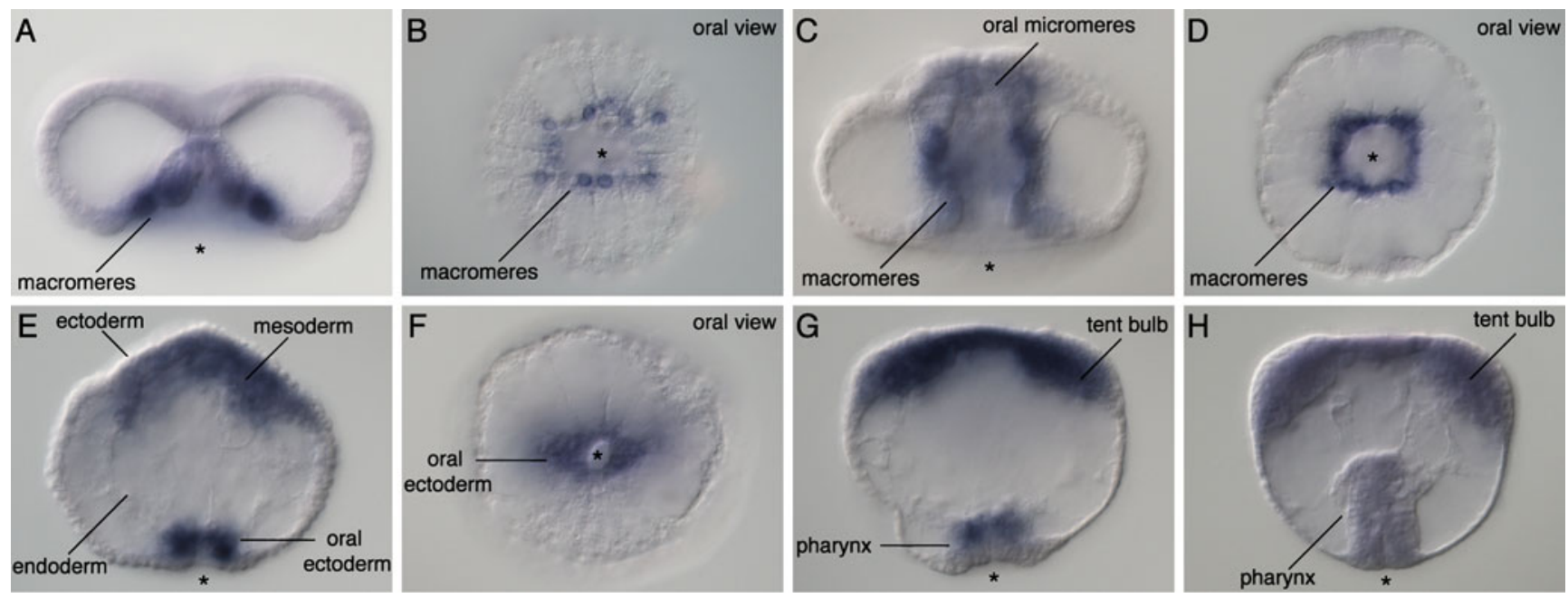

Fig. 3 Developmental expression of $M l C O E$ in the ctenophore, $M$. leidyi. a, c, e, $\mathbf{g}, \mathbf{h}$ Lateral view with the asterisk denoting the blastopore. b, d, f Oral view. a, b At $3 \mathrm{hpf}, M I C O E$ is expressed in the macromeres (endoderm). c, d At $4 \mathrm{hpf}$, the $\mathrm{MlCOE}^{+}$macromeres have completely gastrulated and expression is present in the oral micromeres (mesoderm) which have entered the blastocoel. e, f At $6 \mathrm{hpf}$, $M l C O E$ expression in the macromeres has decreased while expression

remains in the descendents of the oral micromeres which line the aboral part of the blastocoel, as well as in oral ectoderm around the blastopore. $\mathrm{g}$ Expression is similar at $8 \mathrm{hpf}$ in the mesoderm of the forming tentacle bulb and near the blastopore, which forms part of the pharynx. h At 9 hpf, when the comb plates have fully formed, MlCOE expression becomes more diffuse in the pharynx and tentacle bulb. In subsequent stages, we do not detect MICOE expression 


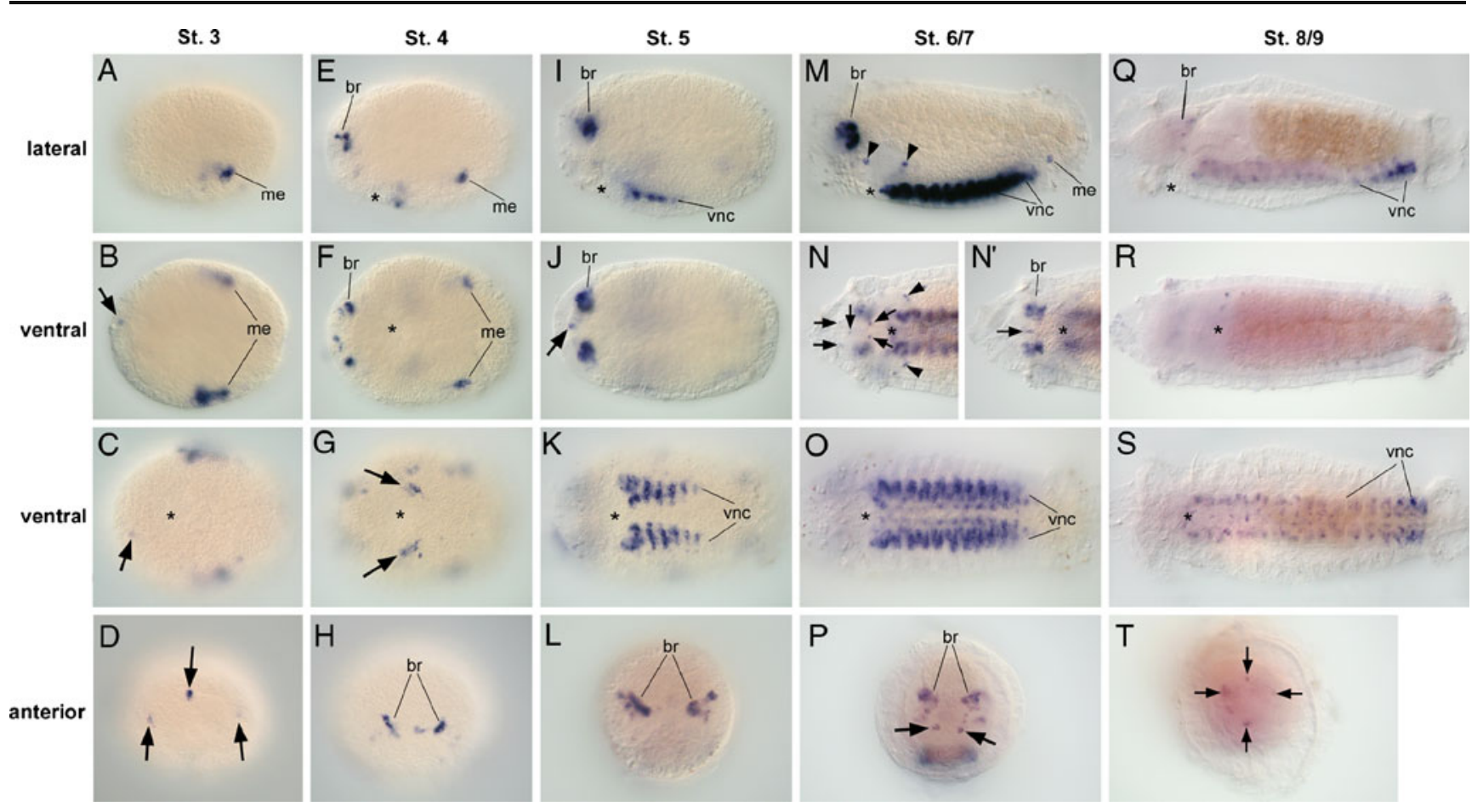

Fig. 4 Developmental expression of $C t C O E$ in the polychaete Capitella teleta. a, e, i, m, q Lateral; $\mathbf{b}, \mathbf{c}, \mathbf{f}, \mathbf{g}, \mathbf{j}, \mathbf{k}, \mathbf{n}, \mathbf{n},, \mathbf{o}, \mathbf{r}, \mathbf{s}$ ventral; and $\mathbf{d}, \mathbf{h}, \mathbf{l}, \mathbf{p}, \mathbf{t}$ anterior views. Anterior is to the left in all panels except $\mathbf{d}, \mathbf{h}, \mathbf{l}, \mathbf{p}, \mathbf{t}$. In $\mathbf{d}, \mathbf{h}, \mathbf{l}, \mathbf{p}, \mathbf{t}$, dorsal is up. a-d In St. 3 embryos, $C t C O E$ is expressed in the trunk mesoderm and a small number of ectodermal cells in the head (arrows). e-h St. 4 larvae show expression in a subset of cells in the forming brain $(\mathbf{e}, \mathbf{f}, \mathbf{h})$; ectodermal cells in the head (f, h); a mesodermal cell cluster $(\mathbf{e}, \mathbf{f})$ and cells in the presumptive subesophageal ganglion (g, arrows). i-l In St. 5 larvae, $C t C O E$ is expressed in a subset of cells in the brain $(b r$ in $\mathbf{i}, \mathbf{j}$, I), in the forming ventral nerve cord ( $v n c$ in $\mathbf{i}, \mathbf{k}$ ) and subsurface anterior cells (j, arrow). $\mathbf{m}-\mathbf{p}$ In St. 6 larvae, $C t C O E$ is prominently expressed in the brain $(\mathbf{m}, \mathbf{p})$ and $\mathrm{VNC}(\mathbf{m}, \mathbf{o})$. In addition, there are small $C t C O E$-expressing clusters associated with the foregut $(\mathbf{m}, \mathbf{n}$, arrowheads) and head (n, n' and $\mathbf{p}$, arrows). $\mathbf{n}$ (more ventral) and $\mathbf{n}^{\prime}$ (more dorsal) are different focal planes of the same specimen. q-t In late larval stages (St. 8,9), $\mathrm{CtCOE}$ is expressed in a small subset of VNC cells (q, $\mathbf{s}$, compare with the broad VNC expression during St. 6). Expression in the brain at this stage is largely undetectable $(\mathbf{q}, \mathbf{r})$ except in a small number of posterior cells (q, $\mathbf{t}$, arrows). Abbreviations are as follows: $b r$ (brain), me (mesoderm), vnc (ventral nerve cord). The position of the mouth is demarcated with a black asterisk conserved function of COE in both vertebrate and invertebrate hematopoiesis (Hartenstein 2006). Detailed analysis of COE activity during fruit fly development indicates that collier (the fruit fly ortholog of $C O E$ ) is also involved in specification of muscle subtypes (Crozatier and Vincent 1999; Baumgardt et al. 2007; Dubois et al. 2007). This suggests that COE may have had an ancestral role in specifying mesodermal derivatives.

Besides mesodermal expression in H. asinina, C. teleta and Chaetopterus, COE transcripts also are detected in the developing central nervous system and in other putative neural elements. In the mollusc $H$. asinina, $C O E$ is expressed in the supra- and subesophageal ganglia (labelled as spg and sbg in Fig. 6c, d, g, h, k, l) while in Chaetopterus and C. teleta, COE is expressed in the developing brain (labelled as br in Figs. 5, 6 and 7) and ventral nerve cord (labelled as vnc in Figs. 5, 6 and 7). These results indicate that COE likely plays a role in neural specification in these animals. Outside of the developing central nervous system, $C O E$ is detected in the apical tuft of
H. asinina (labelled as at in Fig. 6). In Chaetopterus, ChCOE is expressed in dorso-apical ectoderm (labelled as de in Fig. 7) but not in apical tuft cells (labelled with a red asterisk in Fig. 7). In C. teleta, $\mathrm{CtCOE}$ is expressed in a small number of cells in the central, anterior ectoderm (Fig. 4h, arrows in Fig. 4j, n, n', p). Among these three lophotrochozoans, C. teleta is the only larva that lacks an apical tuft. In addition to apical ectodermal expression, strong COE expression is detected in the posterior ectodermal cells of $H$. asinina (pc in Fig. 6a, e, m-o) and Chaetopterus (Fig. $7 \mathrm{a}-\mathrm{h}, \mathrm{m}-\mathrm{O}$ ), but not in C. teleta (Fig. $4 \mathrm{a}-\mathrm{j}$, r). Interestingly, in both $H$. asinina (Hinman et al. 2003) and Chaetopterus (NPM, unpublished data), but not in C. teleta (NPM, unpublished data), neurons are present in this posterior region. Thus, the posterior ectodermal domain of $C O E$ expression may also be involved in neural specification.

$\mathrm{COE}^{+}$cells are also associated with the stomodeum of $H$. asinina (Fig. 6f) and foregut of C. teleta (Fig. 4g, m, n). In C. teleta, this labelling initially appears as two clusters, each one lateral to the stomodeum (arrows in Fig. 4g). At 

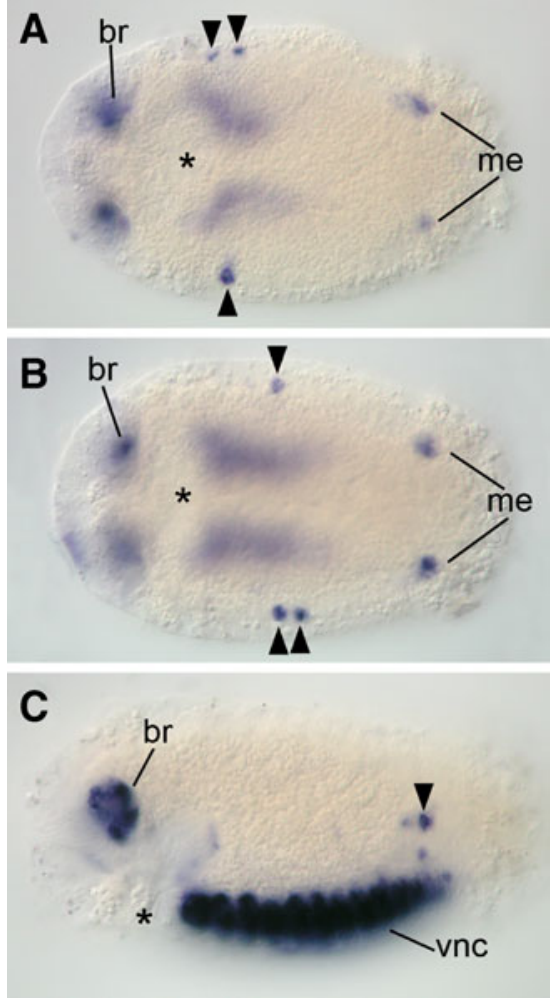

Fig. 5 Transient expression of $C t C O E$ in lateral cell clusters and mesodermal cells. Anterior is to the left in all panels $\mathbf{a}, \mathbf{b}$ ventral views, c lateral view. As development proceeds, $C t C O E$ is sequentially expressed in one to two lateral subsurface clusters (arrowheads) in anterior (a, early St. 5), middle (b, mid-stage 5) and posterior (c, stage 6) segments. Abbreviations are as follows: $b r$ (brain), me (mesoderm), vnc (ventral nerve cord). The position of the mouth is demarcated with a black asterisk

later stages, $\mathrm{COE}^{+}$cells are in two clusters of one to two cells each, closely associated with, but outside the foregut epithelium. The position and appearance of these small $\mathrm{COE}^{+}$clusters is most consistent with them being neural elements. COE is also transiently expressed in the foregut of M. leidyi (Fig. 3e-h). In contrast, $C O E$ is not detected near the region of the future mouth of cnidarian (Pang et al. 2004) or sea urchin (Figs. 8a; 12) representatives. As COE has not yet been implicated in the specification of the larval or adult mouth in any metazoan taxa, we suggest the stomodeal/foregut $C O E$ expression we observe in some trochophore larvae may be acting downstream of 'mouth specifying' genes.

Sea urchin expression In the sea urchin, SpCOE is first detected at around $24 \mathrm{~h}$ post-fertilisation with transcripts diffusely localised to the apical end of the embryo (data not shown). By $44 \mathrm{~h}, S p C O E$ is expressed in three clear loci in the apical organ (Fig. 8a). SpCOE expression is not detected around the blastopore (Fig. 8a) as in M. leidyi, nor is it detected in mesodermal cells as in M. leidyi and the lophotrochozoans analysed.
In summary, these and previously reported results demonstrate both similarities and differences in $C O E$ expression patterns from various metazoan taxa. We detected a clear $C O E$ expression in the mesoderm of the ctenophore (Fig. 3a-g) and all three lophotrochozoan species: H. asinina (Fig. 6a, b, j); Chaetopterus (Fig. 7a, b, e, f, i, j); C. teleta (Fig. 4a, b, e, f) but not in $S$. purpuratus (Fig. 8a). Furthermore, COE is expressed in the developing central nervous system of all three lophotrochozoan species examined (Fig. 4, 5, 6 and 7) and in putative neural elements in the apical organs of both $H$. asinina and S. purpuratus (Figs. 6a-c; 8a) but not Chaetopterus (Fig. 7a-g, k, 1).

\section{Functional characterization of COE in S. purpuratus}

To determine whether $\mathrm{SpCOE}$ functions in neuronal and/or ciliary tuft specification in the apical ganglion of sea urchin larvae, we knocked down SPCOE translation with morpholino anti-sense oligonucleotides (MASOs) and assayed the resulting phenotypes by WMISH for $S p C O E$, SpNK2.1, and the ciliary marker Sptektin 3 and by immunofluorescence labelling of serotonin and synaptogamin B. Previously, Dunn et al. (2007) showed that $S p$ NK2.1 is upstream of several ciliary markers and that abrogation of $S p \mathrm{NK} 2.1$ function resulted in the absence of ciliary marker transcripts ( $\alpha 2$ tubulin, radial spoke 3, tektin3, RSH p63 and dynein $p 33)$ and the apical tuft itself. Here, we show that injection of an $\mathrm{SpCOE}-\mathrm{MASO}$ had no affect on its own expression (Fig. 8a; cf. 8b). This suggests that $S p C O E$ is not autoregulated in the sea urchin apical plate, unlike Drosophila-COE which autoregulates after gastrulation in cells of the posterior intercalary and anterior mandibular segments (Crozatier et al. 1999). Furthermore, like $S p N K 2.1$ (Fig. 8f; cf. 8d), $S p \mathrm{COE}$ does not regulate $S p N K 2.1$ expression (Fig. 8e; cf. 8d). Conversely, injection of an $S p$ NK2.1MASO resulted in the abrogation of $S p C O E$ transcripts (Fig. 8a; cf. 8c) suggesting that $S p C O E$ acts downstream of $S p$ NK2.1. Unlike the $S p$ NK2.1-MASO phenotype (Dunn et al. 2007), knockdown of COE resulted in the apparently normal expression of the cilia marker Sptektin3 (Fig. 8h; cf. $8 \mathrm{~g}$ ), the presence of an apparently normal apical tuft and larvae with normal swimming behaviour.

Because these data suggest that $\mathrm{SpCOE}$ is not involved in fate specification of apical tuft ciliary cells, we next asked if $S p C O E$ is involved in specification of apical ganglion cells. The exact number of serotonergic neurons present in the apical ganglion of dipleurula larvae is stage dependent. Thus, we used carefully matched cohorts of embryos to determine the effects of SpCOE-MASO injection. In 72-h embryos, control MASO-injected larvae had a mean of $2.3 \pm 0.28(n=18)$ serotonergic neurons in the apical ganglion, which was not significantly different from 


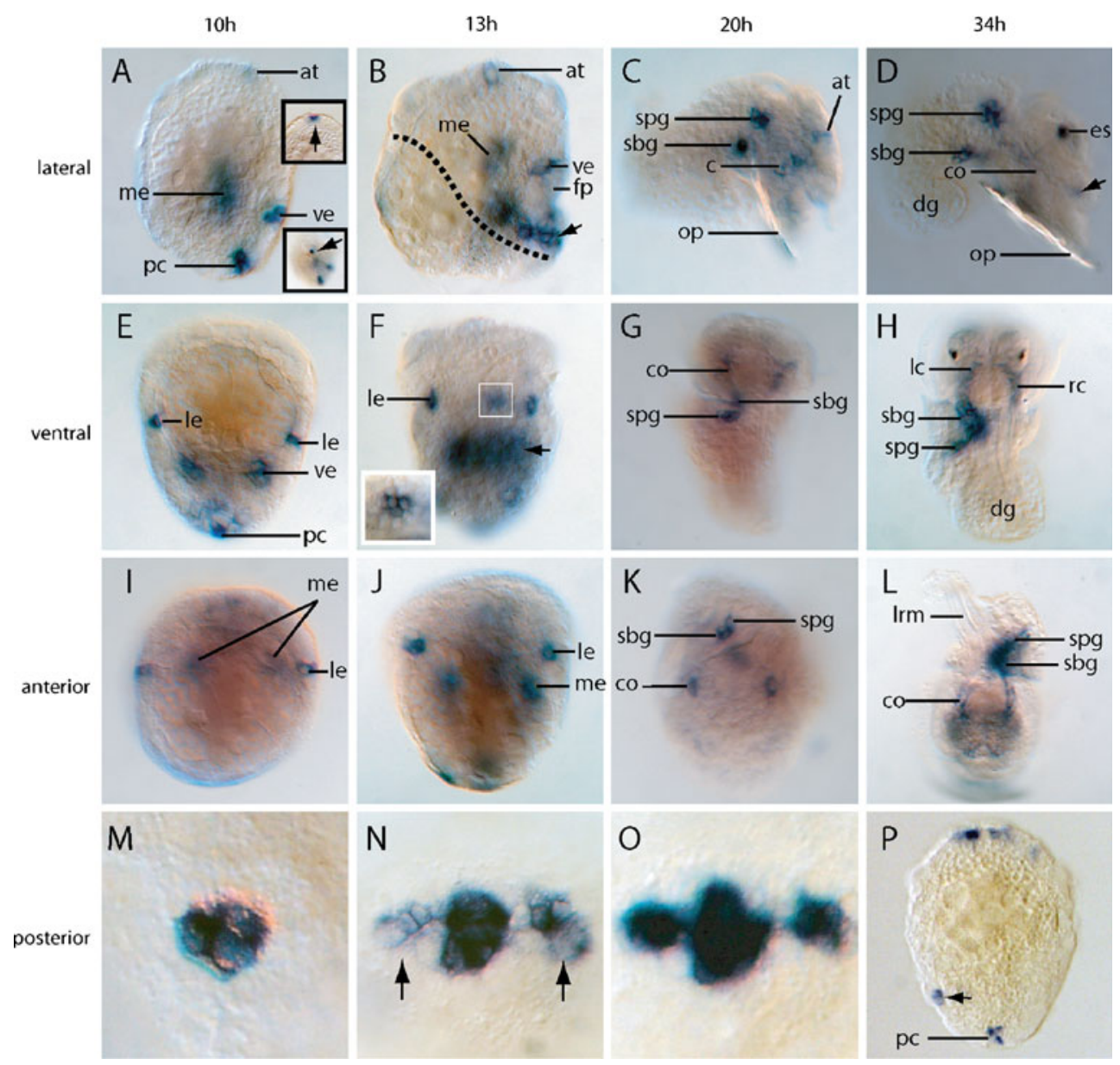

Fig. 6 Developmental expression of HasCOE and HasElav in the tropical abalone Haliotis asinina. Orientations are a-d lateral; $\mathbf{e}, \mathbf{f}, \mathbf{p}$ ventral; $\mathbf{g}$ and $\mathbf{h}$ dorsal; $\mathbf{i}-\mathbf{I}$ apical/anterior; $\mathbf{m}-\mathbf{0}$ posterior. $\mathbf{a}, \mathbf{e}, \mathbf{i}$ Has COE expression in a hatched $(10 \mathrm{hpf})$ trochophore larva, with expression detected in a group of posterior cells $(p c)$, paraxial mesodermal bands (me), a pair of ventral ectodermal cells (ve) and within the apical tuft (at). Upper inset in (a) shows expression in the apical tuft (vertical arrow), lower inset shows an individual cell associated with the lateral ectoderm (black arrow, the white arrow in this inset indicates the $\mathrm{COE}^{+}$paraxial mesodermal bands in a lower focal plane). b, f, j $13 \mathrm{hpf}$ trochophore larva prior to torsion. A band of expression marking the division between the foot primordia $(f p)$ and the expanding shell field (approximately indicated by the dashed line) has developed (arrow). The boxed region in $\mathrm{F}$ is expanded in the inset and highlights a triplet of $\mathrm{COE}^{+}$cell within the vicinity of the stomodeum. c, g, k A 20-hpf larva (post-torsion) with HasCOE expression within the apical tuft and the presumed supraesophageal

uninjected larvae (mean $=2.4 \pm 0.22, n=19)$ (Figs. 9 and 10). In both sets of control larvae (MASO control injected and uninjected), serotonergic cells were distributed with bilateral symmetry and projected neurites toward the midline, contributing to the apical organ neuropil (Fig. 9). Larvae derived from eggs injected with $S p$ NK2.1-MASO had a significantly higher mean number of serotonergic neurons in the apical ganglion (mean=3.6 $\pm 0.15, n=20 ; p<0.001$ ). The serotonergic neurons in these larvae had bifurcating (spg) and subesophageal ganglia (sbg). Cells that will later form connectives $(c o)$ between the esophageal and pedal ganglia are also visible. The refractive operculum $(o p)$ can also be seen. d, h, l A 34hpf veliger with a well-developed eyespot (e), operculum and digestive gland $(d g)$. The supra- and subesophageal ganglia maintain expression of HasCOE and faint expression is also detected within the anterior of the foot (arrow). The fibres of the larval retractor muscle (lrm) are also visible. $\mathbf{m}-\mathbf{o}$ Representative variation in the spatial expression of $\mathrm{HaSCOE}^{+}$posterior cells (labelled $p c$ in a) viewed posteriorly between individual 10-h-old larvae. Expression ranges from (m) a distinct triplet of closely associated cells to (n) a group of cells with an additional lateral population of $\mathrm{COE}^{+}$cells (arrows), through to (o) strong expression of HasCOE in the lateral and central groups. p A ventral view of a 10-hpf trochophore larva expressing HasElav in apical ectodermal cells associated with the apical tuft, a pair of lateral ectodermal cells (arrow) and a set of ectodermal posterior cells $(p c)$

neurites with terminal growth cones that projected in random directions and lacked an obvious bilateral distribution (Fig. 9c). Larvae derived from eggs injected with $S p$ COE-MASO had a mean of $4.5 \pm 0.15$ serotonergic neurons $(n=18)$, which also differed significantly from controls $(p<0.001)$ and from SpNK2.1-MASO-injected larvae $(p<0.05)$. In these embryos, the neurons were tightly clustered within the apical ganglion and contributed neurites to the neuropil (Fig. 9d). These data suggest that 

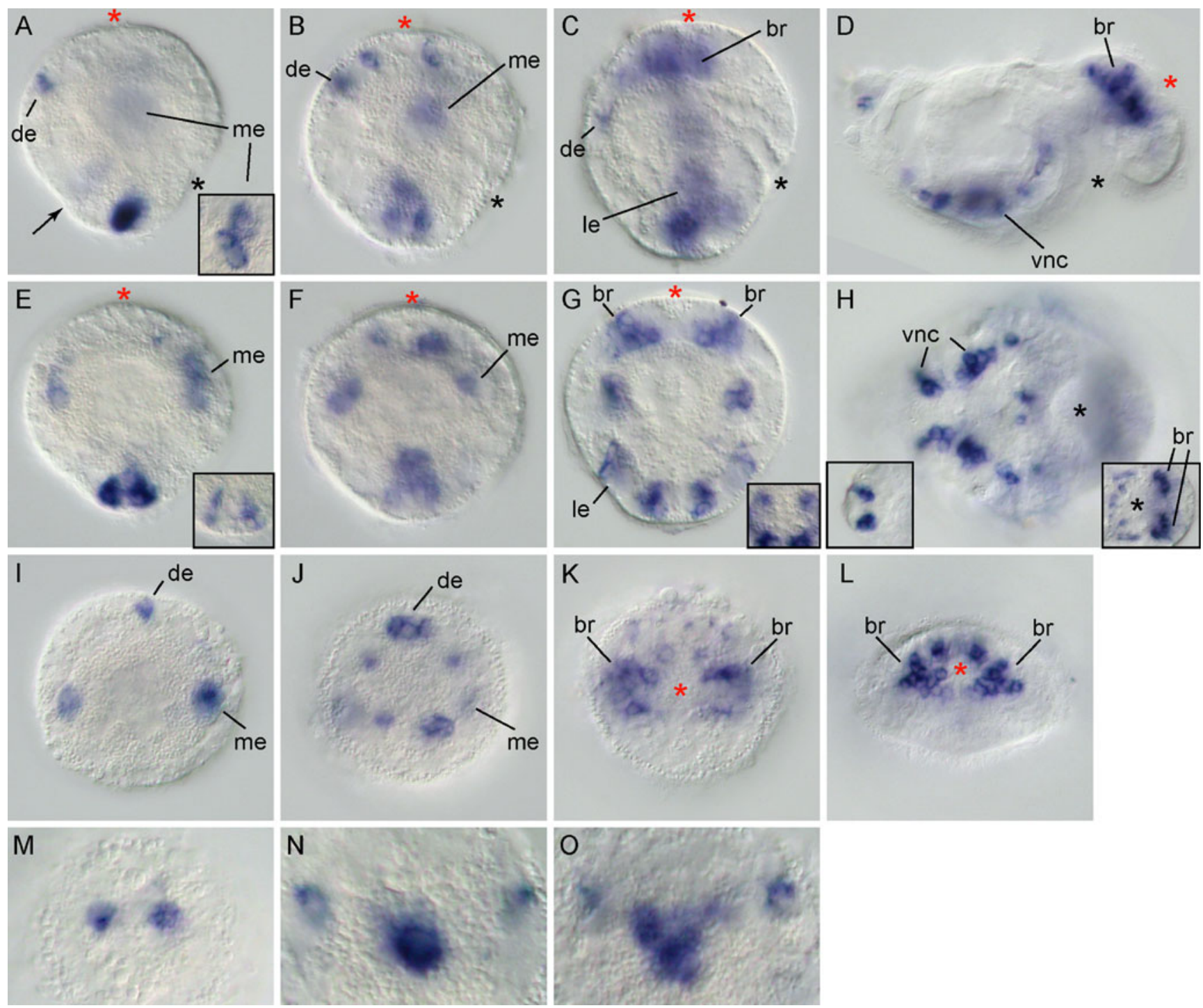

Fig. 7 Developmental expression of ChCOE in the polychaete Chaetopterus a-d lateral; e, f, h ventral; $\mathbf{g}$ dorsal; i-l anterior; $\mathbf{m}-\mathbf{0}$ posterior views. Anterior is up in $\mathbf{a}-\mathbf{c}$ and $\mathbf{e}-\mathbf{g}$ and to the right in $\mathbf{d}$ and h. Dorsal is up in $\mathbf{i}-\mathbf{o}$. a, e, $\mathbf{i}, \mathbf{m}$ In $11 \mathrm{hpf}$ trochophore larvae, ChCOE transcripts are detected in two posterior groups of cells (e, m); two lateral groups of cells presumed to be mesoderm ( $m e$ in $\mathbf{a}, \mathbf{e}$ and i); and a dorsal, anterior ectodermal cell ( $d e$ in $\mathbf{a}$ and $\mathbf{i}$ ). The inset in $\mathbf{a}$ is a more superficial focal plane of the same animal showing the $\mathrm{ChCOE}^{+}$ mesodermal cells which vary in number (one to three) from left to right. The animal shown in the inset in $\mathbf{e}$ and in panel $\mathbf{m}$ is of a different animal for which the colour reaction was not incubated as long. The posterior group of cells also can be variable in number. At this stage, there are occasional $\mathrm{ChCOE}^{+}$ectodermal cells in the region of the forming brain but not the apical tuft (position is marked with a red asterisk). ChCOE is also expressed in posterior, dorsolateral ectodermal patches (arrow in a). b, f, j, o $15 \mathrm{hpf}$ trochophore larvae have similar clusters of $\mathrm{ChCOE}^{+}$cells as the $11 \mathrm{hpf}$ animals. By this stage, the dorsal ectodermal cluster $(d e)$ has expanded to three to five cells $(\mathbf{j})$, and the $\mathrm{ChCOE}^{+}$cells in the region of the forming brain are more visible but are still not localised around the apical tuft $(\mathbf{b}, \mathbf{f}, \mathbf{j})$. The posterior region of $C h C O E$ expression consists of a central group of cells and two $\mathrm{ChCOE}^{+}$cells positioned just anterior and dorsal to the central posterior patch (o). This is similar to the posterior pattern of expression at $13 \mathrm{hpf}(\mathbf{n})$, although the central, posterior $\mathrm{ChCOE}^{+}$ patch is just one cell at this stage. c, g, k At $19 \mathrm{hpf}$, ChCOE is expressed in clusters of ectodermal cells that appear to prefigure the central nervous system. ChCOE is expressed in the developing brain $(\mathbf{c}, \mathbf{g}, \mathbf{k})$, in a dorsal ectodermal patch of cells (de in $\mathbf{c})$ and in clusters of cells in the lateral $(l e)$ and posterior ectoderm $(\mathbf{c}, \mathbf{d})$. There are also two clusters of $\mathrm{ChCOE}^{+}$cells on either side of the mouth, which may be neural or mesodermal. In addition, there are two small clusters of $\mathrm{ChCOE}^{+}$cells in the ventral ectoderm (inset in $\mathbf{g}$, anterior cluster of $\mathrm{ChCOE}^{+}$cells). The animal in the inset in $\mathbf{g}$ is a different animal for which the colour reaction was carried out longer. The two posterior clusters of $\mathrm{ChCOE}^{+}$cells correspond to the posterior ectodermal $\mathrm{ChCOE}^{+}$cell clusters in $\mathbf{g .} \mathbf{d}, \mathbf{h}, \mathbf{l}$ In L2-L3 animals (d, $46 \mathrm{hpf} ; \mathbf{h}$ and l, $72 \mathrm{hpf}$ ), ChCOE is expressed in subsets of the forming central nervous system, including in the developing brain ( $b r$ in $\mathbf{d}$, right inset in $\mathbf{h}$ and $\mathbf{l}$ ), the forming ventral nerve cord ( $v n c$ in $\mathbf{d}, \mathbf{h})$ and in clusters of posterior neural cells in the pygidium (left inset in $\mathbf{h}$ ). There is a patch of $\mathrm{ChCOE}^{+}$cells in the ventral ectoderm just posterior to the mouth (h) as well as single $\mathrm{ChCOE}^{+}$cells around the posterior edge of the mouth (right inset in $\mathbf{h}$ ), which spatially correspond to the subesophageal connective. $b r$, brain; de, dorsal ectodermal cluster; $l e$, lateral ectoderm; me, mesoderm; vnc, ventral nerve cord. The position of the mouth is demarcated with a black asterisk and the apical tuft with a red asterisk 


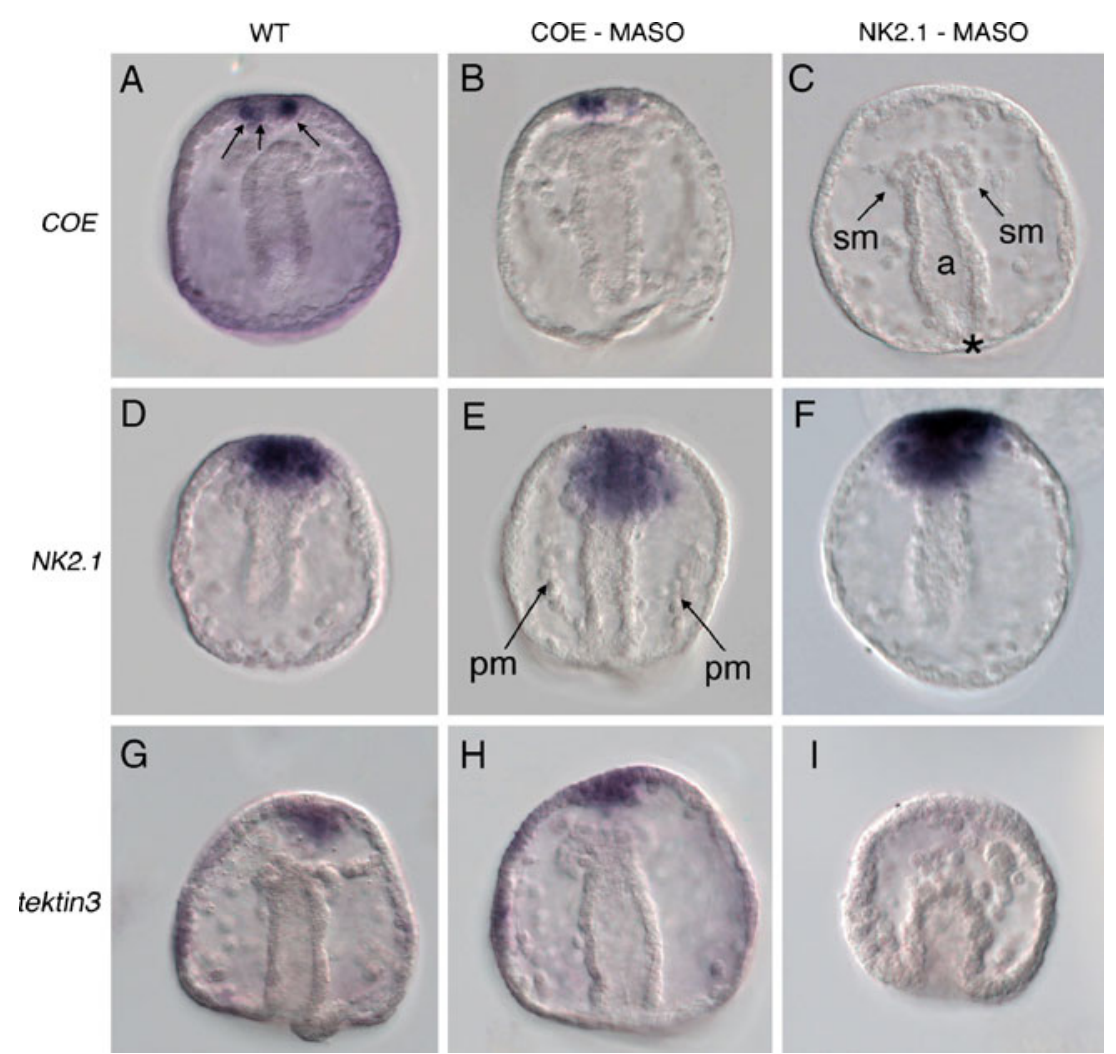

Fig. 8 Expression of $S p C O E, S p N K 2.1$ and Sptektin3 in normal and MASO-injected embryos. a Expression of $S p C O E$ in wild type (WT) embryo. Expression is clearly seen in three distinct loci at the apical end of the embryo (arrows). SPCOE expression is never detected in either the primary $(\mathrm{pm})$ or secondary mesenchyme $(\mathrm{sm})$ cells. b, c Injection of the SpCOE-MASO (b), unlike the SpNK2.1 MASO (c), has no affect on $S p C O E$ expression, suggesting that $S p C O E$ is downstream of $S p$ NK2.1, but does not autoregulate. d Expression of $S p N K 2.1$ in WT embryo in the apical domain (Takacs et al. 2004). e, $\mathbf{f}$ $S p N K 2.1$ expression in embryo injected with $\operatorname{SpCOE}$ (e) and $\operatorname{SpNK2.1}$

$S p \mathrm{COE}$ and $S p \mathrm{NK} 2.1$ (possibly via $S p \mathrm{COE}$ ) are involved in apical neuronal specification and differentiation. Specifically, $S p C O E$ appears to suppress serotonergic differentiation in the apical tuft of dipleurula larvae.

The expression data from lophotrochozoans and the functional results in $S$. purpuratus suggest that $\mathrm{COE}$ may have functioned ancestrally to repress the specification of serotonergic neurons. In $H$. asinina, serotonin-positive cells are absent from the posterior end of the larvae (Hinman et al. 2003) where strong $C O E$ expression is detected. $\mathrm{FMRF}^{+}$cells are present in this region of Aplysia californica (Dickinson et al. 2000) Ilyanassa obsoleta (Dickinson and Croll 2003) and H. asinina (Cummins, Croll and Degnan unpublished data) trochophores. The expression of the pan-neuronal marker HasElav (Perrone-Bizzozero and Bolognani 2002; BenitoGutiérrez et al. 2005; Marlow et al. 2009) in this region of $H$. asinina trochophores (Fig. 6p) further supports the hypothesis that non-serotonergic neurons will be born here. In Chaetopterus, a single, large 'horn-shaped' posterior serotonergic (f) MASO is unchanged suggesting that $S p N K 2.1$ is not downstream of $S p \mathrm{COE}$, and does not autoregulate. $\mathbf{g}$ Expression of the cilia gene tektin3 in WT embryo in apical domain. $\mathbf{h}, \mathbf{i}$ Injection of embryos with SpCOE-MASO does not alter tektin3 expression (h), whereas expression is abrogated upon introduction of the SpNK2.1 MASO (i) suggesting that $S p \mathrm{COE}$ does not regulate apical tuft development. Abbreviations: $a$, archenteron; $p m$, primary mesenchyme; $s m$, secondary mesenchyme. The position of the blastopore is indicated with a black asterisk

neuron is visible by the end of gastrulation ( $\sim 9 \mathrm{hpf})$; however, there are likely other, non-serotonergic neurons that form in this region at similar times (NPM, unpublished data). $C$. teleta larvae do not posses posterior serotonergic neurons and do not express $C O E$ posteriorly. It will be interesting to functionally determine whether $\mathrm{COE}$ represses serotonergic cell fate in annelids and molluscs as it does in S. purpuratus.

\section{Conserved mesodermal expression of $C O E$}

A principle feature of the $C O E$ expression patterns we have described here is expression in mesodermal tissues in ctenophore, annelid and molluscan representatives. While the fates of these tissues are not yet known, it is of note that one of the first two papers to isolate and characterise the function of COE (from a vertebrate) was to describe its role in $\mathrm{B}$ cell specification, a mesoderm derivative and a type of immune cell primarily responsible for antibody production (Hagman et al. 1993). Recently, a role for COE 

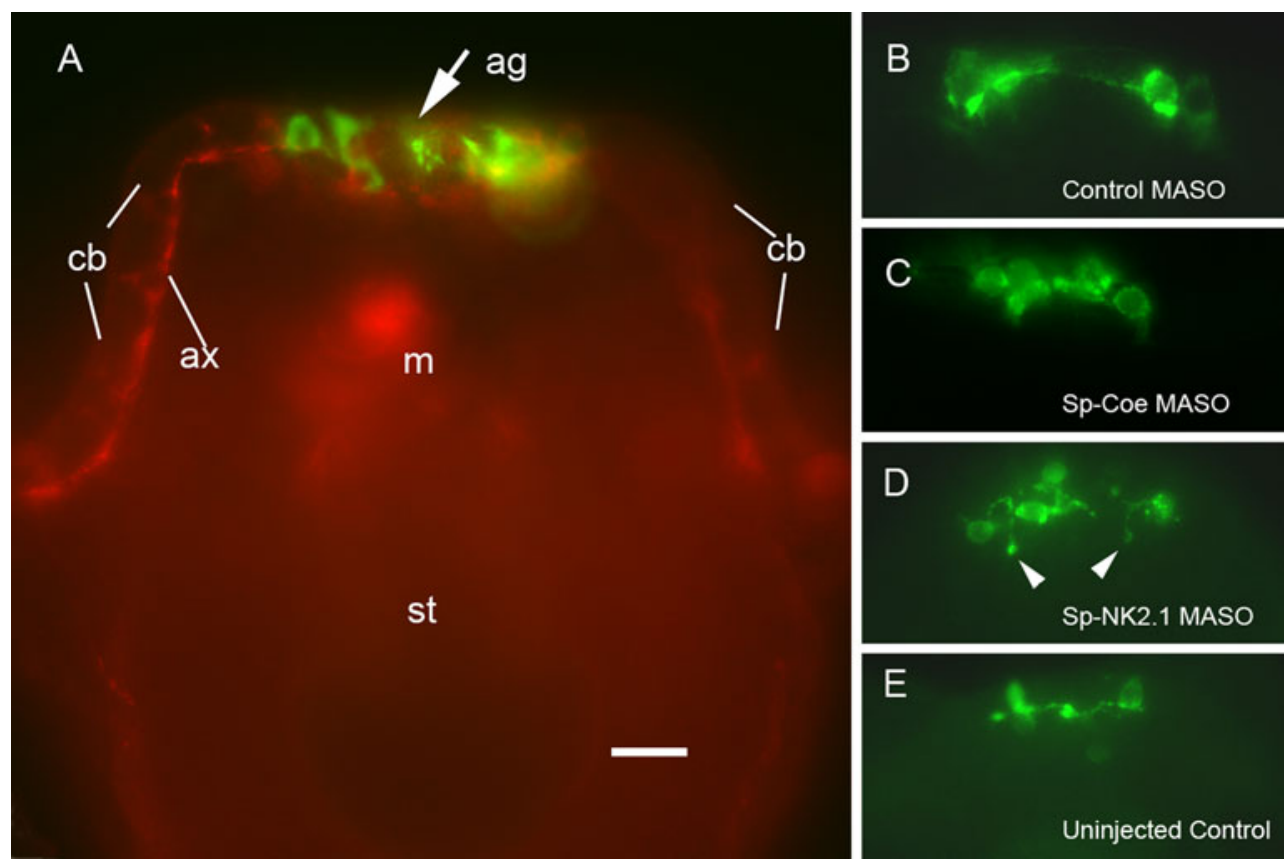

Fig. 9 Immunofluorescent images of morpholino injected larvae $72 \mathrm{~h}$ post-fertilisation. a Image of an uninjected larva combining the antiserotonergic (green) and anti-synaptogamin (red) signals showing the location of the apical ganglion (arrow, ag). b Example of a control MASO-injected embryo that was used to quantify the number of serotonergic cells in the apical organs of 72-h larvae. c An example of an $\mathrm{SpCOE-MASO-injected} \mathrm{embryo} \mathrm{in} \mathrm{which} \mathrm{there} \mathrm{are} \mathrm{supernumerary}$

in blood cell homeostasis was also reported for Drosophila where it is involved in the differentiation of immune cells (lamellocytes) following parasitisation (Crozatier et al. 2004; Krzemien et al. 2007). Activity in haematopoietic precursors is therefore likely to be a deeply conserved

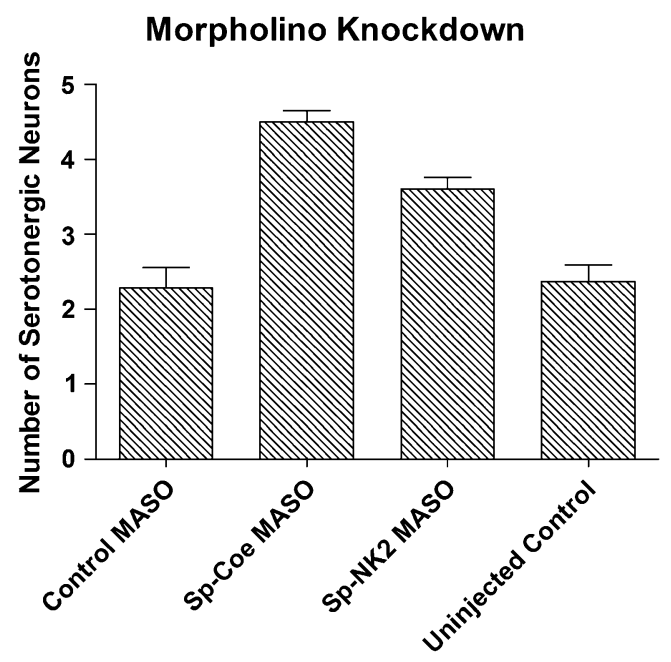

Fig. 10 Effect of SpCOE-MASO knockdown on the number of serotonergic neurons in the apical organ. Carefully staged embryos were prepared for immunofluorescence and the number of serotonergic neurons counted. Abrogation of $S p \mathrm{COE}$ and $S p \mathrm{NK} 2.1$ translation results in a significantly higher number of serotonergic neurons in the apical organ compared to wild type and control larvae serotonergic neurons. d $S p N K$ 2.1-MASO-injected embryos had more serotonergic cells than controls and projections with terminal growth cones (arrowheads) were not restricted to the neuropil of the apical ganglion. e Example of an apical organ in an uninjected control from the stage-matched set of embryos used to quantify cells in the apical organ. $a g$, apical organ; $a x$, axonal tracts of ciliary bands; $c b$, ciliary bands; $m$, mouth; st, stomach. Scale bar in $\mathbf{a}=10 \mu \mathrm{M}$

feature of $C O E$, with the possibility of it having had a specific role in the evolution of the metazoan immune system (Hartenstein 2006). If COE also specifies haematopoietic cells in spiralians, then this function likely arose shortly after the split of cnidarians from the bilateria. Alternatively, $C O E$ may function in distinct mesodermal cell types in spiralians. Interpreting the expression of $C O E$ in early mesodermal derivatives of $M$. leidyi is challenging because the phylogenetic position of ctenophores is currently unstable (Dunn et al. 2008; Pick et al. 2010), and ctenophores do not have a circulatory system (Brusca and Brusca 2002).

\section{A $C O E$ cell type molecular fingerprint in ectodermally} derived apical ciliated structures

Most marine invertebrates develop via a planktonic larval period (here defined as indirect development) during which either active (by means of swimming) or passive (current driven) dispersal is achieved (Brusca and Brusca 2002). Prior to settlement and metamorphosis, many species must identify a suitable substrate upon which to attach (Jackson et al. 2002). It is believed that apical organs are involved in recognising metamorphosisinducing cues via chemoreception (Hadfield et al. 2000; Leise et al. 2001; Thavaradhara and Leise 2001). Eluci- 
dating the evolutionary origins of these structures across a variety of metazoan phyla has the potential to address questions of larval homology and more broadly whether the ancestor of the Metazoa developed indirectly or directly. Previously, Dunn et al. (2007) conducted a comparative GRN analysis of two transcription factors (NK2.1 and HNF6) and their regulation of genes required for apical tuft ciliation in the sea urchin S. purpuratus and the abalone Haliotis rufescens. They found significant differences in the synexpression of these genes and concluded that the apical tufts of urchins and abalone are specified in different ways and are therefore unlikely to have the same evolutionary origins. Given its clear ecological role and restriction to primary marine larvae, the apical tuft is an appropriate structure to evaluate the homology of the apical organ; however, a difficulty with the Dunn et al. (2007) study is that although the dissimilarity between the trochophore (Haliotis) and dipleurula ( $S$. purpuratus) was clear, the primary gene under investigation, $N K 2.1$, does not have a clear homolog in cnidarians (Ryan et al. 2006), and hence evolutionary polarity could not be unambiguously established. Expression of COE in the apical organ of cnidarians could suggest potential homology and indeed a parsimonious interpretation of our $C O E$ data per se would be that the apical ganglia of urchins, abalone and cnidarians are homologous; however an alternative hypothesis that $C O E$ functions in the apical ganglion to specify chemosensory neurons and that this cell type was independently recruited to the apical region in multiple metazoan lineages, must also be considered. Such a scenario would fall under Nielsen's definition of homocracy-expression of homologous genes in non-homologous structures. While our $C O E$ data alone cannot distinguish between these hypotheses, our functional data clearly indicate that at least in the sea urchin it is not involved in apical tuft specification, but in the specification of proper neuronal cell fate within the ganglion itself.

\section{Conclusion}

We anticipate that more detailed analyses of COE regulation and function and the inclusion of more metazoan representatives that posses larval apical tufts, will significantly contribute to the resolution of the larval homology problem. Homologous genomic outputs such as $C O E$, which represent the genetic material upon which evolution acted to diversify cell types during the early history of metazoan evolution, are well suited for such studies. Our data has generated testable hypotheses and will serve as a platform for future studies aimed at resolving the evolutionary histories of larval and adult metazoan body plans. Our findings also highlight the need for functional assays to be developed for a wider range of metazoan model systems, which will complement the flood of sequence data the field of evo-devo is now experiencing.

Acknowledgments This work was supported by the Australian Research Council through funding to BMD and DJJ, and Deutsche Forschungsgemeinschaft funding to DJJ and the Courant Research Centre for Geobiology, Göttingen, through the German Excellence Initiative. RDB is supported by a Discovery Grant from the Natural Sciences and Engineering Research Council of Canada. KJP and ECS are supported by the National Science Foundation (IOS0923754 to ECS).

Ethical standards All experiments described here comply with the current laws and regulations of the respective countries they were conducted in.

Conflict of interest The authors declare no conflicts of interest.

Open Access This article is distributed under the terms of the Creative Commons Attribution Noncommercial License which permits any noncommercial use, distribution, and reproduction in any medium, provided the original author(s) and source are credited.

\section{References}

Adamska M, Matus DQ, Adamski M et al (2007) The evolutionary origin of hedgehog proteins. Curr Biol 17:R836-R837. doi:10.1016/j.cub.2007.08.010

Akerblad P, Lind U, Liberg D et al (2002) Early B cell factor (O/E-1) is a promoter of adipogenesis and involved in control of genes important for terminal adipocyte differentiation. Mol Cell Biol 22:8015-8025. doi:10.1128/MCB.22.22.8015-8025.2002

Arendt D (2005) Genes and homology in nervous system evolution: comparing gene functions, expression patterns, and cell type molecular fingerprints. Theor Biosci 124:185-197. doi:10.1016/j. thbio.2005.08.002

Arendt D (2008) The evolution of cell types in animals: emerging principles from molecular studies. Nat Rev Gen 9:868-882. doi:10.1038/nrg2416

Baumgardt M, Miguel-Aliaga I, Karlsson D et al (2007) Specification of neuronal identities by feedforward combinatorial coding. PLoS Biol 5:e37. doi:10.1371/journal.pbio.0050037

Benito-Gutiérrez E, Illas M, Comella JX et al (2005) Outlining the nascent nervous system of Branchiostoma floridae (amphioxus) by the pan-neural marker AmphiElav. Br Res Bull 66:518-521. doi:10.1016/j.brainresbull.2005.03.007

Blake JA, Grassle JP, Eckelbarger KJ (2009) Capitella teleta, a new species designation for the opportunistic and experimental Capitella sp. I, with a review of the literature for confirmed records. Zoosym 2:25-53

Boyle MJ, Seaver EC (2010) Expression of FoxA and GATA transcription factors correlates with regionalized gut development in two lophotrochozoan marine worms: Chaetopterus (Annelida) and Themiste lageniformis (Sipuncula). EvoDevo 2010, 1:2 doi:10.1186/2041-9139-1-2

Brusca RC, Brusca GJ (2002) Invertebrates. Sinauer, Sunderland 
Carroll SB, Grenier JK, Weatherbee SD (2001) From DNA to diversity: molecular genetics and the evolution of animal design. Blackwell Science, Malden

Chapman JA, Kirkness EF, Simakov O et al (2010) The dynamic genome of Hydra. Nature 464:592-596. doi:10.1038/nature08830

Corradi A, Croci L, Broccoli V et al (2003) Hypogonadotropic hypogonadism and peripheral neuropathy in Ebf2-null mice. Development 130:401-410. doi:10.1242/dev.00215

Crozatier M, Vincent A (1999) Requirement for the Drosophila COE transcription factor Collier in formation of an embryonic muscle: transcriptional response to notch signalling. Development 126:1495-1504

Crozatier M, Valle D, Dubois L et al (1996) Collier, a novel regulator of Drosophila head development, is expressed in a single mitotic domain. Curr Biol 6:707-718. doi:10.1016/S0960-9822(09)00452-7

Crozatier M, Valle D, Dubois L et al (1999) Head versus trunk patterning in the Drosophila embryo; collier requirement for formation of the intercalary segment. Development 126:4385-4394

Crozatier M, Glise B, Vincent A (2002) Connecting Hh, Dpp and EGF signalling in patterning of the Drosophila wing; the pivotal role of collier/knot in the AP organiser. Development 129:42614269

Crozatier M, Ubeda J, Vincent A et al (2004) Cellular immune response to parasitization in Drosophila requires the EBF orthologue collier. PLoS Biol 2:E196. doi:10.1371/journal. pbio.0020196

Daburon V, Mella S, Plouhinec JL et al (2008) The metazoan history of the COE transcription factors. Selection of a variant HLH motif by mandatory inclusion of a duplicated exon in vertebrates. BMC Evol Biol 8:131. doi:10.1186/1471-2148-8-131

Davidson EH (2006) The regulatory genome. Academic, San Diego

Dickinson AJ, Croll RP (2003) Development of the larval nervous system of the gastropod Ilyanassa obsoleta. J Comp Neurob 466:197-218. doi:10.1002/cne.10863

Dickinson AJ, Croll RP, Voronezhskaya EE (2000) Development of embryonic cells containing serotonin, catecholamines, and FMRFamide-related peptides in Aplysia californica. Biol Bull 199:305-315

Dubois L, Bally-Cuif L, Crozatier M et al (1998) XCoe2, a transcription factor of the Col/Olf-1/EBF family involved in the specification of primary neurons in Xenopus. Curr Biol 8:199209

Dubois L, Enriquez J, Daburon V et al (2007) Collier transcription in a single Drosophila muscle lineage: the combinatorial control of muscle identity. Development 134:4347-4355. doi:10.1242/ dev.008409

Dunn CWD, Hejnol A, Matus DQ et al (2008) Broad phylogenomic sampling improves resolution of the animal tree of life. Nature 452:745-749. doi:10.1038/nature06614

Dunn EF, Moy VN, Angerer LM et al (2007) Molecular paleoecology: using gene regulatory analysis to address the origins of complex life cycles in the late Precambrian. Evol Dev 9:10-24. doi:10.1111/j.1525-142X.2006.00134.X

Edgar R (2004) MUSCLE: a multiple sequence alignment method with reduced time and space complexity. BMC Bioinform 5:113. doi:10.1186/1471-2105-5-113

Garcia-Dominguez M, Poquet C, Garel S et al (2003) Ebf gene function is required for coupling neuronal differentiation and cell cycle exit. Development 130:6013-6025. doi:10.1242/dev.00840

Garel S, Marín F, Mattéi MG et al (1997) Family of Ebf/Olf-1-related genes potentially involved in neuronal differentiation and regional specification in the central nervous system. Dev Dyn 210:191-205

Hadfield MG, Meleshkevitch EA, Boudko DY (2000) The apical sensory organ of a gastropod veliger is a receptor for settlement cues. Biol Bull 198:67-76
Hagman J, Belanger C, Travis A et al (1993) Cloning and functional characterization of early B cell factor, a regulator of lymphocytespecific gene expression. Genes Dev 7:760-773

Hartenstein V (2006) Blood cells and blood cell development in the animal kingdom. Ann Rev Cell Dev Biol 22:677-712. doi:10.1146/annurev.cellbio.22.010605.093317

Hejnol A, Martindale MQM, Henry JQ (2007) High-resolution fate map of the snail Crepidula fornicata: the origins of ciliary bands, nervous system, and muscular elements. Dev Biol 305:63-76. doi:10.1016/j.ydbio.2007.01.044

Hinman VF, O'Brien EK, Richards GS et al (2003) Expression of anterior Hox genes during larval development of the gastropod Haliotis asinina. Evol Dev 5:508-521. doi:10.1046/j.1525142X.2003.03056.X

Jackson DJ, Leys SP, Hinman VF et al (2002) Ecological regulation of development: induction of marine invertebrate metamorphosis. Int J Dev Biol 46:679-686

Jackson DJ, Ellemor N, Degnan BM (2005) Correlating gene expression with larval competence, and the effect of age and parentage on metamorphosis in the tropical abalone Haliotis asinina. Mar Biol 147:681-697. doi:10.1007/s00227-005-1603-Z

Jackson DJ, Wörheide G, Degnan BM (2007) Dynamic expression of ancient and novel molluscan shell genes during ecological transitions. BMC Evol Biol 7:160. doi:10.1186/1471-2148-7-160

Krzemien J, Dubois L, Makki R et al (2007) Control of blood cell homeostasis in Drosophila larvae by the posterior signalling centre. Nature 446:325-328. doi:10.1038/nature05650

Larroux C, Fahey B, Liubicich D et al (2006) Developmental expression of transcription factor genes in a demosponge: insights into the origin of metazoan multicellularity. Evol Dev 8:150-173. doi:10.1111/j.1525-142X.2006.00086.X

Leise EM, Thavaradhara K, Durham NR et al (2001) Serotonin and nitric oxide regulate metamorphosis in the marine snail Ilyanassa obsoleta. Am Zool 41:258-267

Liberg D, Sigvardsson M, Akerblad P (2002) The EBF/Olf/Collier family of transcription factors: regulators of differentiation in cells originating from all three embryonal germ layers. Mol Cell Biol 22:8389-8397. doi:10.1128/MCB.22.24.8389-8397.2002

Marlow HQ, Srivastava M, Matus DQ et al (2009) Anatomy and development of the nervous system of Nematostella vectensis, an anthozoan cnidarian. Dev Neur 69:235-254. doi:10.1002/ dneu.20698

Martindale MQ (2005) The evolution of metazoan axial properties. Nat Rev Gen 6:917-927. doi:10.1038/nrg1725

Martindale MQM, Hejnol A (2009) A developmental perspective: changes in the position of the blastopore during bilaterian evolution. Dev Cell 17:162-174. doi:10.1016/j.devcel.2009.07.024

Matus DQ, Pang K, Marlow H et al (2006) Molecular evidence for deep evolutionary roots of bilaterality in animal development. Proc Natl Acad Sci USA 103:11195-11200. doi:10.1073/pnas.0601257103

Mella S, Soula C, Morello D (2004) Expression patterns of the coe/ebf transcription factor genes during chicken and mouse limb development. Gen Exp Pat 4:537-542. doi:10.1016/j.modgep.2004.02.005

Nakajima Y, Kaneko H, Murray G et al (2004) Divergent patterns of neural development in larval echinoids and asteroids. Evol Dev 6:95-104. doi:10.1111/j.1525-142X.2004.04011.x

Nielsen C, Martinez P (2003) Patterns of gene expression: homology or homocracy? Dev Gen Evol 213:149-154

Pang K, Martindale MQM (2008) Developmental expression of homeobox genes in the ctenophore Mnemiopsis leidyi. Dev Gen Evol 218:307-319. doi:10.1007/s00427-008-0222-3

Pang K, Matus DQ, Martindale MQ (2004) The ancestral role of $C O E$ genes may have been in chemoreception: evidence from the development of the sea anemone, Nematostella vectensis (Phylum Cnidaria; Class Anthozoa). Dev Gen Evol 214:134-138. doi:10.1007/S00427-004-0383-7 
Perrone-Bizzozero N, Bolognani F (2002) Role of HuD and other RNA-binding proteins in neural development and plasticity. $\mathrm{J}$ Neurosci Res 68:121-126

Peterson KJ (2005) Macroevolutionary interplay between planktic larvae and benthic predators. Geology 33:929-932. doi:10.1130/ G21697.1

Pick K, Hervé P, Fabian S et al (2010) Improved phylogenomic taxon sampling noticeably affects non-bilaterian relationships. Mol Biol Evol 29(9):1983-1987. doi:10.1093/molbev/msq089

Pozzoli O, Bosetti A, Croci L et al (2001) Xebf3 is a regulator of neuronal differentiation during primary neurogenesis in Xenopus. Dev Biol 233:495-512. doi:10.1006/dbio.2001.0230

Prasad BC, Ye B, Zackhary R et al (1998) unc-3, a gene required for axonal guidance in Caenorhabditis elegans, encodes a member of the $\mathrm{O} / \mathrm{E}$ family of transcription factors. Development 125:1561-1568

Putnam N, Srivastava M, Hellsten U et al (2007) Sea anemone genome reveals ancestral eumetazoan gene repertoire and genomic organization. Science 317:86-94. doi:10.1126/science.1139158

Putnam N, Butts T, Ferrier DE et al (2008) The amphioxus genome and the evolution of the chordate karyotype. Nature 453:10641071. doi: $10.1038 /$ nature 06967

Ryan J, Burton P, Mazza M et al (2006) The cnidarian-bilaterian ancestor possessed at least 56 homeoboxes: evidence from the starlet sea anemone, Nematostella vectensis. Gen Biol 7:R64. doi:10.1186/gb-2006-7-7-R64

Sea Urchin Genome Sequencing Consortium (2006) The genome of the sea urchin Strongylocentrotus purpuratus. Science 314:941952. doi:10.1126/science. 1133609
Srivastava M, Simakov O, Chapman J et al (2010) The Amphimedon queenslandica genome and the evolution of animal complexity. Nature 466:720-726. doi:10.1038/nature09201

Stolfi A, Gainous TB, Young JJ et al (2010) Early chordate origins of the vertebrate second heart field. Science 329:565-568. doi:10.1126/science. 1190181

Takacs CM, Amore G, Oliveri P et al (2004) Expression of an NK2 homeodomain gene in the apical ectoderm defines a new territory in the early sea urchin embryo. Dev Biol 269:152-164. doi:10.1016/j.ydbio.2004.01.023

Talavera G, Castresana J (2007) Improvement of phylogenies after removing divergent and ambiguously aligned blocks from protein sequence alignments. Sys Biol 56:564-577. doi:10.1080/ 10635150701472164

Thamm K, Seaver ECS (2008) Notch signaling during larval and juvenile development in the polychaete annelid Capitella sp. I. Dev Biol 320:304-318. doi:10.1016/j.ydbio.2008.04.015

Thavaradhara K, Leise EM (2001) Localization of nitric oxide synthase-like immunoreactivity in the developing nervous system of the snail Ilyanassa obsoleta. J Neurocytol 30:449-456

Travis A, Hagman J, Hwang L et al (1993) Purification of early B cell factor and characterization of its DNA-binding specificity. Mol Cell Biol 13:3392-3400

Wang MM, Reed RR (1993) Molecular cloning of the olfactory neuronal transcription factor Olf-1 by genetic selection in yeast. Nature 364:121-126. doi:10.1038/364121a0

Wheeler BM, Heimberg AM, Moy VN et al (2009) The deep evolution of metazoan microRNAs. Evol Dev 11:50-68. doi:10.1111/j.1525-142X.2008.00302.x 